\title{
Análise da microbacia do Ribeirão Grande por meio de geotecnologias
}

\author{
Moisés Pereira Galvão Salgado ${ }^{1}$ \\ ${ }^{1}$ Divisão de Sensoriamento Remoto - DSR \\ Instituto Nacional de Pesquisas Espaciais - INPE \\ Caixa Postal 515 - 12201-970 - São José dos Campos - SP, Brasil \\ Tel. (12) 3945-6437 \\ salgado@dsr.inpe.br \\ Getulio Teixeira Batista ${ }^{2}$ \\ ${ }^{2}$ Universidade de Taubaté (UNITAU) \\ Programa de Pós-Graduação em Ciências Ambientais \\ Estrada Mun. Dr. José Luiz Cembranelli, 5.000 - Bairro Itaim \\ CEP 12.081-010 - Taubaté, SP, Brasil \\ Tel. (12) 3625-4116 / Fax (12) 3632-8956 \\ getulio@agro.unitau.com.br
}

\begin{abstract}
This paper aim to describe the land-cover and the morfometric characteristics of the Ribeirão Grande watershed. The Permanent Preservation Areas (APP) created by Brazilian Forest Law 4771/65 on the study area were mapped and the land-cover in these areas was investigated. The land-cover was classified using a TM/Landsat-5 image and the morfometrics characteristics were based on SRTM digital elevation model. The results indicated high erosion and flood risks.
\end{abstract}

Palavras-chave: GIS, image processing, environmental preservation, SIG, processamento de imagens, preservação ambiental.

\section{Introdução}

A Serra da Mantiqueira, nome Tupi que significa "montanha que chora" devido à grande quantidade de nascentes em suas encostas e ao intenso regime de chuvas, é caracterizada por regiões de relevo acidentado e clima tropical quente e úmido. $\mathrm{O}$ crescimento da atividade antrópica na microbacia do Ribeirão Grande, localizada na Serra da Mantiqueira, no município de Pindamonhangaba - SP, associado às características da região, tem resultado em prejuízos ambientais, como o assoreamento e alteração dos cursos d'água, inundações, voçorocas e mudanças da cobertura vegetal em Áreas de Preservação Permanente (APP).

As bacias hidrográficas são unidades que possibilitam estudar o ciclo da água e as interferências do homem sobre esse ciclo. $\mathrm{O}$ desenvolvimento de geotecnologias capazes de processar dados cartográficos (e.g. hidrografia) integrados a dados provenientes de sensores orbitais (e.g. imagens satelitais e modelos digitais de elevação) tornou possível o estudo detalhado de microbacias hidrográficas.

O escoamento superficial em uma bacia hidrográfica é um dos componentes mais importantes como indicador da adequabilidade do sistema de manejo daquela bacia. Ele ocorre a partir do momento em que a intensidade de precipitação supera a capacidade de infiltração do solo. O escoamento superficial está diretamente relacionado com as precipitações que ocorrem em uma bacia hidrográfica, com as características físicas da mesma e com a cobertura vegetal do terreno.

Dados morfométricos definem uma série de parâmetros relacionados com o comportamento hidrológico das microbacias. Existe uma estreita correspondência entre o regime hidrológico e as características físicas, sendo, portanto, de grande utilidade prática o 
conhecimento destes elementos. Civco et al. (1995) destacam que embora a caracterização de bacias hidrográficas não seja uma novidade para cientistas e planejadores, suas possibilidades e aplicações tornaram-se exponencialmente maiores com a evolução dos Sistemas de Informações Geográficas (SIGs), contribuindo para o estudo de microbacias por meio de análise de dados georreferenciados, tanto na representação do modelo numérico do terreno, como na caracterização do uso e ocupação do solo da bacia.

De acordo com Silva e Pruski (2005), o uso de SIG permite agregar, em um único aplicativo, a capacidade de mapear características e de associá-las em banco de dados, o que permite análises espaciais de maneira eficiente e em um curto espaço de tempo.

Um aspecto importante na caracterização de microbacias é o mapeamento das APP previstas no Código Florestal (Lei 4.771/65), pois ela dá amparo legal para a preservação e recuperação dessas áreas. As APP foram criadas com o objetivo de proteger o ambiente natural visando o benefício público. Assim, estas áreas devem estar cobertas com a vegetação natural (CATELANI e BATISTA, 2007). De acordo com Costa et al. (1996), a cobertura vegetal nessas áreas atenua o escoamento superficial e conseqüentemente os efeitos erosivos e a lixiviação dos solos.

Sheng et al. (1997) propõem o uso de SIG para classificação e avaliação de bacias hidrográficas destacando a importância de ferramentas, como o modelo digital de elevação, na obtenção de parâmetros como limite da bacia, elevações e características das encostas que podem ser combinadas com outras informações, como mapa geológico, hidrológico, ecológico, entre outros, para derivar mapas temáticos.

Neste contexto, o presente artigo objetivou a caracterização física da microbacia do Ribeirão Grande, por meio de recursos de SIG, técnicas de geoprocessamento e sensoriamento remoto, visando ilustrar as condições da cobertura do solo e aspectos morfométricos da microbacia, de modo a atender demandas de práticas de conservação e fiscalização ambiental na região.

\section{Metodologia de Trabalho}

A caracterização física da microbacia do Ribeirão Grande foi realizada utilizando-se as ferramentas do aplicativo SPRING. Criou-se uma base de dados para análise e processamento dos dados georreferenciados utilizando-se a projeção UTM e modelo da Terra SAD69.

As variáveis morfométricas e o índice de vegetação "Normalized Difference Vegetation Index" (NDVI) foram calculados, para a análise das características físicas da microbacia, por meio de geoprocessamento e processamento da imagem TM/Landsat-5, de 30 de agosto de 2009, órbita 218 e ponto 076. Utilizaram-se dados vetorizados das cartas do IBGE folhas SF23-Y-B-V-2, SF-23-Y-B-V-4, SF-23-Y-B-VI-1, SF-23-Y-B-VI-3 para identificação das linhas de drenagem na microbacia.

Foi utilizado o modelo digital de elevação SRTM disponibilizado pela Empresa Brasileira de Pesquisa Agropecuária (EMBRAPA) (MIRANDA, 2005). O trabalho de campo realizado no dia 05/09/2008 possibilitou o registro de fotografias da área de estudo para validação da interpretação visual e análise resultante do processamento da imagem TM/Landsat-5.

O NDVI foi calculado por meio da Equação 1, com base na imagem TM/Landsat-5, após realizada a conversão dos números digitais para valores de reflectância aparente. $\mathrm{O}$ cálculo da reflectância foi realizado por meio da Linguagem Espacial para Geoprocessamento Algébrico (LEGAL), ver Equação 2, onde $K$ é a variável que compensa a excentricidade da órbita terrestre em torno do Sol, $\theta$ corresponde ao ângulo zenital solar de aquisição da imagem, $E$ representa a irradiância solar no topo da atmosfera para o comprimento de onda $\lambda$ e $L o$ a radiância aparente da superfície para o comprimento de onda $\lambda$, calculada utilizando-se os coeficientes de calibração radiométrica descritos por Chander et al. (2009). 


$$
\begin{gathered}
N D V I=\frac{\text { banda } 4-\text { banda } 3}{\text { banda } 4+\text { banda } 3} \\
\text { Reflectância ap. }(\lambda)=\frac{K^{2} \times \pi \times L o(\lambda)}{\mathrm{E}(\lambda) \cos \theta}
\end{gathered}
$$

O mapeamento das APP foi baseado na Lei Federal $n^{\circ}$. 4.771, de 1965 e na Resolução CONAMA n ${ }^{\circ} 303$, de 2002 e seguiu a metodologia descrita por Catelani e Batista (2007) e Oliveira et al., (2006). O mapa de APP gerado foi cruzado com o mapa temático resultante do mapeamento do uso do solo por meio da interpretação visual da imagem TM/Landsat-5 processada. Após realizar a mensuração dos dados fundamentais para a caracterização física da microbacia por meio de ferramenta do aplicativo SPRING como: operações métricas, medidas de classes, tabulação cruzada e extração de topos, foram calculados os parâmetros para a descrição da microbacia.

As variáveis utilizadas para análise e descrição física da microbacia foram:

a) Área $(A)$ e perímetro $(P)$ : parâmetros fundamentais utilizados para o cálculo de outras variáveis morfométricas, definidos com base na linha de cumeada que delimita o divisor de águas da microbacia do Ribeirão Grande.

b) Maior comprimento $(L)$ e largura média $(D m)$ : variáveis expressas em $\mathrm{km}$, determinadas seguindo os critérios adotados por Fontes (1997), sendo o maior comprimento representado pelo comprimento do maior eixo longitudinal da bacia e a largura média resultante da divisão da área pelo maior comprimento.

c) Índice de circularidade (Ic): proposto por Miller (1953 apud Christofoletti, 1974) e é definido como a razão entre a área da bacia e a área do círculo de igual perímetro $(A c)$. Este índice tem significado semelhante ao índice de forma (CHRISTOFOLETTI, 1969 e TAVARES e QUEIROZ, 1981) e ao coeficiente de compacidade (VILLELA e MATTOS, 1980) que correlacionam o perímetro da bacia com a sua área. O índice de circularidade (Equação 3) indica que à medida que o valor se aproxima de 1, a bacia tende à forma circular e, portanto, é mais sujeita a inundação.

$$
I C=\frac{A}{A c}
$$

d) Amplitude altimétrica máxima $(\mathrm{Hm})$ e relação de relevo $(\mathrm{Rr})$ : estão relacionadas com as variações topográficas da bacia e foram apresentadas inicialmente por Schumm (1956). A amplitude altimétrica máxima corresponde à diferença, em metros, entre a altitude do exultório e o ponto mais alto no divisor de águas. A relação de relevo relaciona a amplitude altimétrica com o maior comprimento, indicando que quanto mais elevado o seu valor, maior o desnível entre a cabeceira e foz. Os estudos efetuados por Patton \& Baker (1976) em bacias com altos e baixos potenciais às inundações indicaram a relação de relevo (Equação 4), densidade de drenagem e ordem dos canais como as três variáveis morfométricas mais influentes na indicação de bacias com alto potencial à inundação.

$$
R r=\frac{H m}{L}
$$


e) Índice de sinuosidade (Si): Villela e Mattos (1975) descrevem o grau de sinuosidade dos cursos d'água que constitui um fator controlador da velocidade de escoamento das águas. Corresponde à razão entre o comprimento do rio principal da bacia (Lrio) e o seu comprimento vetorial (Lvet) e pode ser calculado pela seguinte expressão (Equação 5):

$$
S i=\frac{\text { Lrio }}{\text { Lvet }}
$$

f) Densidade de drenagem (Dd): descrita por Horton (1945) como sendo a relação entre o comprimento total dos canais $(L t)$ pela área da bacia hidrográfica $(A)$. A variável retrata a disponibilidade de canais para o escoamento linear das águas e o grau de dissecação do relevo resultante da atuação da rede de drenagem. Ver Equação 6.

$$
D d=\frac{L t}{A}
$$

\section{Resultados e Discussão}

O mapeamento das APP, ilustrado na Figura 1, demonstra que 2946 hectares correspondem à APP de topo de morro, 320 hectares de APP de margens de rios e 23 hectares de APP de nascentes, as demais classes de APP têm áreas desprezíveis.

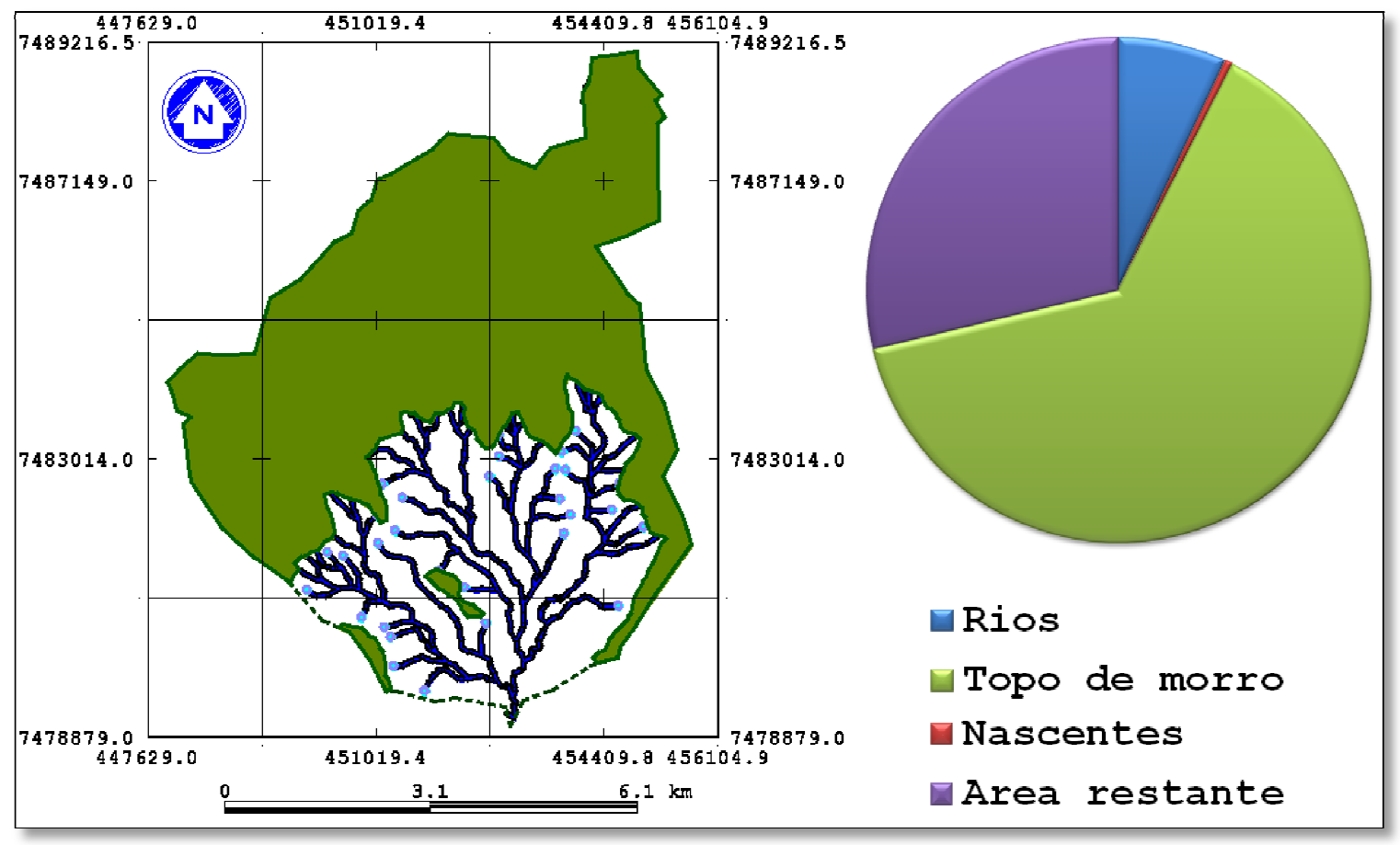

Figura 1. Mapa temático das Áreas de Preservação Permanente da microbacia do Ribeirão Grande, Pindamonhangaba - SP.

O fatiamento do NDVI, ilustrado na Figura 2, indicou que as áreas com valores de NDVI variando de -1 e 0.2 estão relacionadas às áreas de solo exposto, rochas e áreas sombreadas pelo relevo (Tabela 1). As áreas com NDVI variando de 0.2 a 0.6 relacionam-se às áreas de pastagem e, por fim, as áreas que apresentam valores de NDVI entre 0.6 a 1 correspondem às áreas de vegetação mais densa da Mata Atlântica.

A análise da cobertura do solo da microbacia do Ribeirão Grande aponta que 3477 hectares estão cobertos por vegetação nativa da Mata Atlântica, 1101 hectares por pastagens degradadas em áreas declivosas e 42 hectares correspondem à classe solo exposto e rochas. 


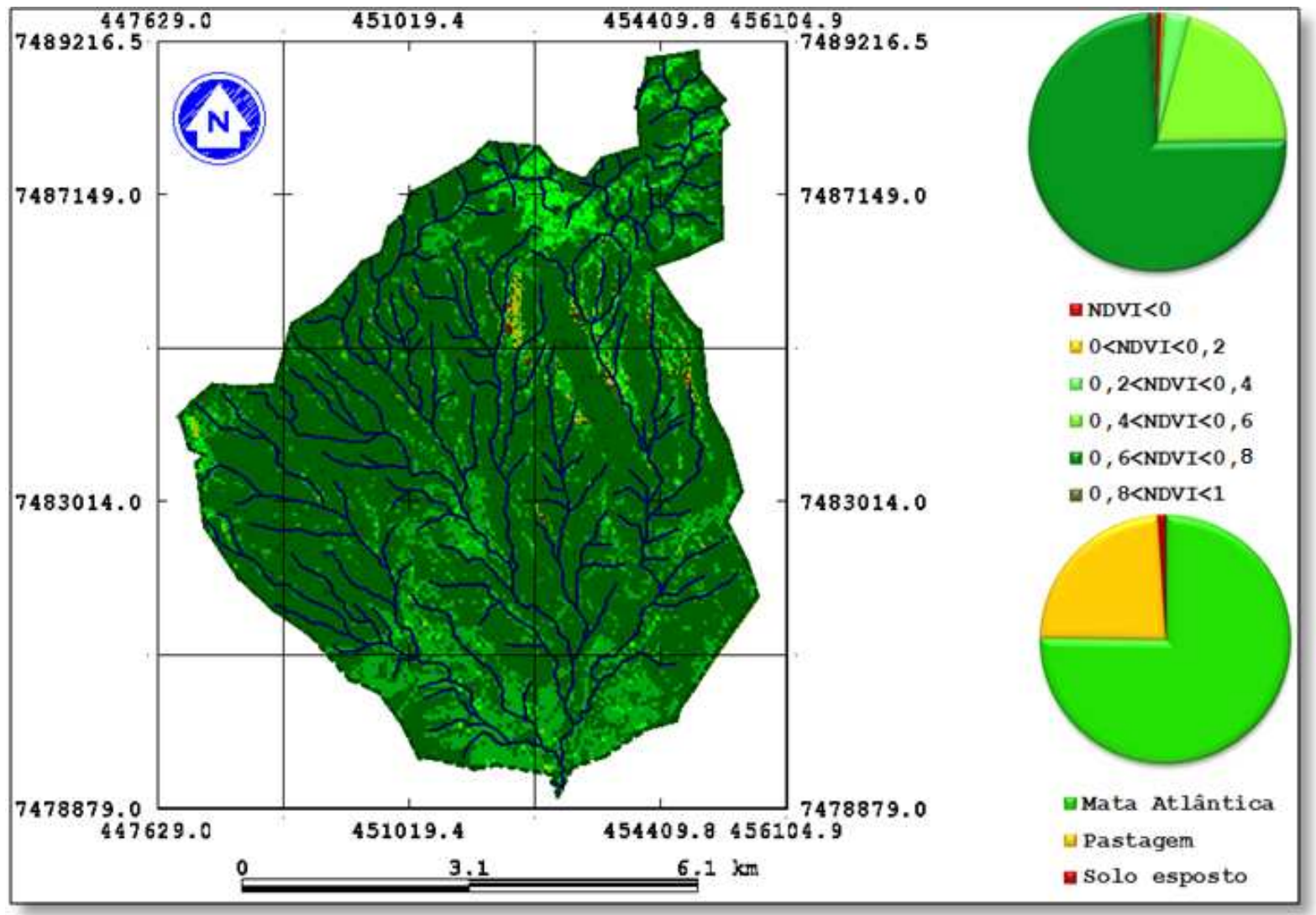

Figura 2. Mapa temático resultante do fatiamento dos valores de NDVI e relação com as classes de cobertura do solo para a microbacia do Ribeirão Grande.

Tabela 1. Valores de NDVI relacionados às áreas da microbacia do Ribeirão Grande.

\begin{tabular}{lcr}
\hline NDVI & Cobertura do solo & Área em hectares \\
\hline NDVI $<\mathbf{0}$ & Solo exposto, rochas e sombra & 22.05 \\
$\mathbf{0}<$ NDVI $<\mathbf{0 . 2}$ & Solo exposto, rochas e sombra & 20.79 \\
$\mathbf{0 . 2}<\mathbf{N D V I}<\mathbf{0 . 4}$ & Pastagens degradadas & 144.06 \\
$\mathbf{0 . 4}<\boldsymbol{N D V I}<\mathbf{0 . 6}$ & Pastagens & 957.93 \\
$\mathbf{0 . 6}<\boldsymbol{N D V I}<\mathbf{0 . 8}$ & Mata atlântica & 3435.6 \\
$\mathbf{0 . 8}<\boldsymbol{N D V I}<\mathbf{1}$ & Mata atlântica & 41.71 \\
\hline
\end{tabular}

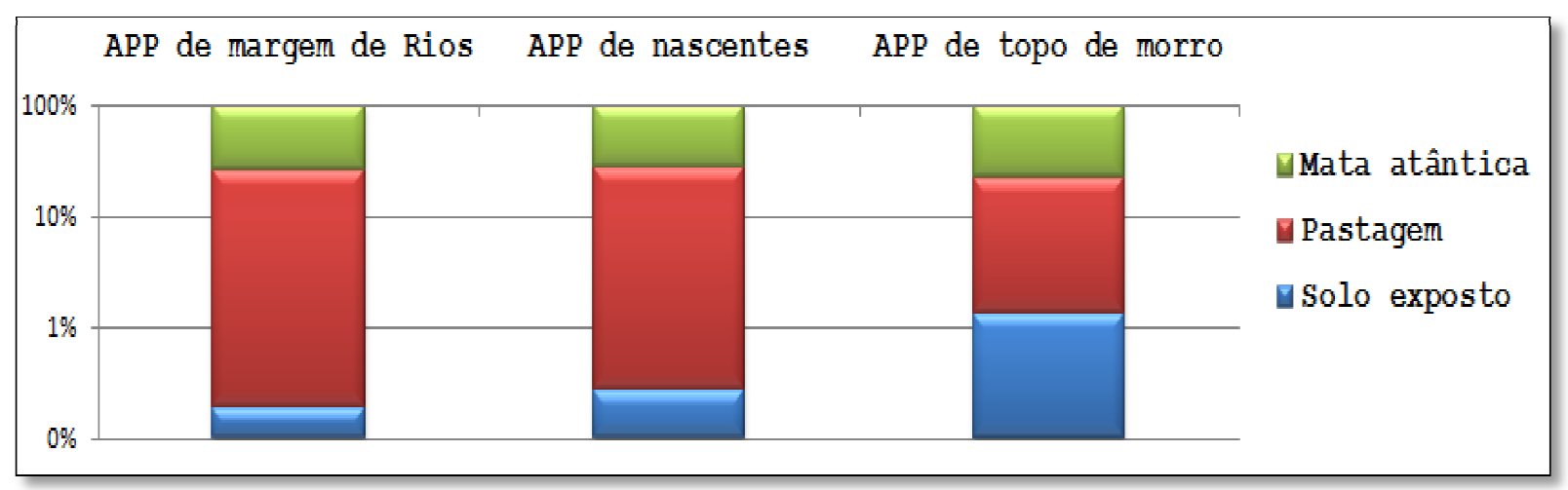

Figura 3. Relação entre a cobertura do solo e Áreas de Preservação Permanente na microbacia do Ribeirão Grande. 
Pode-se observar a predominância da pastagem em relação às outras coberturas do solo nas APP (Figura 3). Estimou-se que 80 hectares de APP de margens de rios, 6 hectares de APP de nascentes e 608 hectares de APP de topo de morro estão ocupados por pastagens. Esta classe de cobertura não se adéqua às condições das APP e pode contribuir para a intensificação dos processos erosivos na microbacia. Ver Figura 4 e Figura 5.

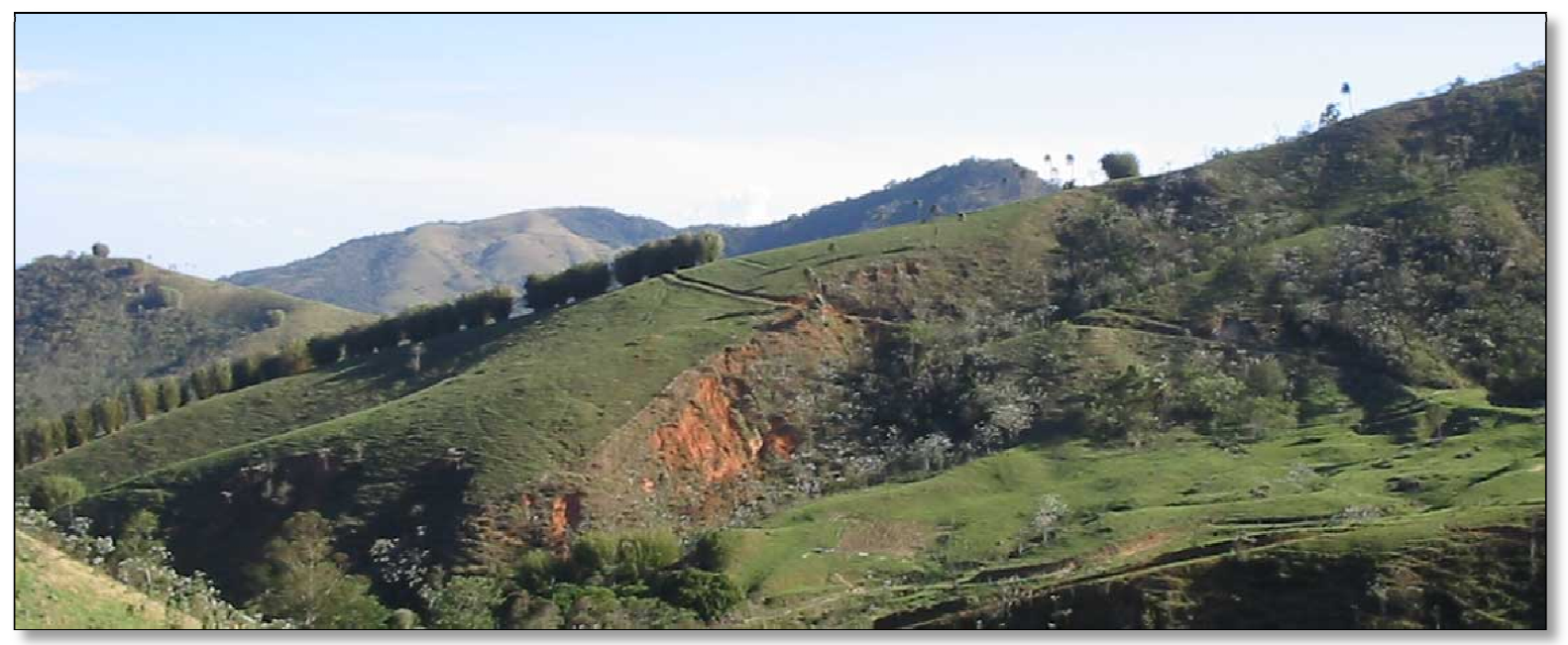

Figura 4. Fotografia de deslizamento de terra e erosão em voçoroca na microbacia do Ribeirão Grande (05/09/2009).

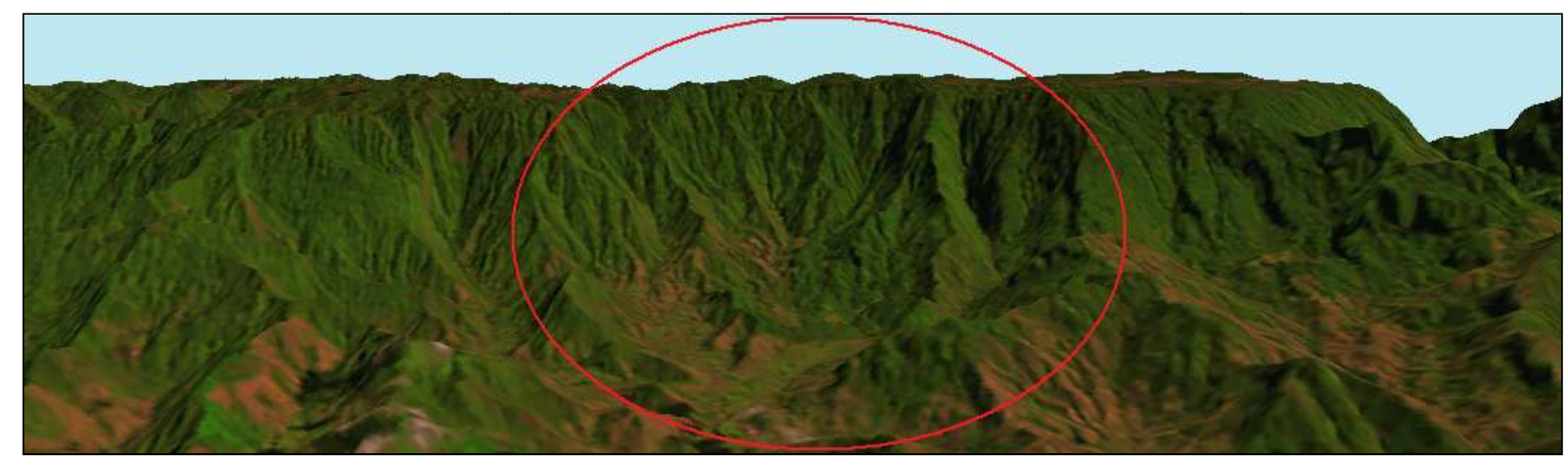

Figura 5. Visualização em perspectiva da imagem TM/Landsat-5 (30/08/2009), composição RGB das bandas 5, 4 e 3, sobreposta ao modelo digital de elevação SRTM

A inadequação da cobertura do solo nas APP associado às características morfométricas da microbacia estão relacionadas com um alto potencial de erosão e podem justificar os correntes prejuízos ambientais, como deslizamentos de terra, voçorocas e inundações. As condições ambientais observadas na microbacia do Ribeirão Grande, agravadas pelo não cumprimento da legislação ambiental vigente, demonstram as necessidades de um planejamento ambiental e fiscalização eficiente, visando reduzir o impacto decorrente da atividade antrópica na região.

De acordo com os resultados da Tabela 2, a sinuosidade $(S i=1.3)$ da microbacia do Ribeirão Grande, relativamente alta, está relacionada a escoamentos em bacias acidentadas (córregos jovens) representado por um alto valor da amplitude altimétrica $(H m=1370 \mathrm{~m}) \mathrm{e}$ pela Relação de relevo $(R r=139.3 \mathrm{~m} / \mathrm{km})$ o que de certo modo contribui para o escoamento rápido da água na bacia. A microbacia do Ribeirão Grande apresenta valores de Densidade de drenagem $(D d=3.1)$ e Índice de circularidade $(I c=0,59)$ indicando ser esta uma bacia com 
características favoráveis a enchentes e erosão hídrica (CHRISTOFOLETTI, 1969; VILLELA \& MATTOS, 1975).

Tabela 2. Características morfométricas da microbacia do Ribeirão Grande.

\begin{tabular}{|c|c|}
\hline Parâmetros & IBGE \\
\hline Área da bacia $(A) \mathrm{km}^{2}$ & 46.2 \\
\hline Perímetro $(P) \mathrm{km}$ & 31.1 \\
\hline Área circular correspondente $(A c) \mathrm{km}^{2}$ & 48.9 \\
\hline Maior comprimento $(L) \mathrm{km}$ & 9.9 \\
\hline Largura média $(\mathrm{Dm}) \mathrm{km}$ & 4.7 \\
\hline Amplitude altimétrica $(\mathrm{Hm}) \mathrm{m}$ & 1375 \\
\hline Comprimento do rio principal (Lrio) $\mathrm{km}$ & 12.8 \\
\hline Comprimento vetorial do rio principal (Lvet) $\mathrm{km}$ & 9.9 \\
\hline Comprimento total da rede de drenagem $(\mathrm{Lt}) \mathrm{km}$ & 142.1 \\
\hline Índice de circularidade (Ic) adimensional & 0.59 \\
\hline Relação de relevo $(R r) \mathrm{m} / \mathrm{km}$ & 139.3 \\
\hline Índice de sinuosidade (Si) adimensional & 1.3 \\
\hline Densidade de drenagem $(D d)$ adimensional & 3.1 \\
\hline
\end{tabular}

\section{Conclusões}

O NDVI calculado com base na imagem TM/Landsat-5 auxiliou na caracterização da cobertura do solo e na detecção de áreas com diferentes coberturas vegetais, sendo que, 74\% das áreas analisadas apresentaram valores de NDVI entre 0,6 a 0,8 e foram identificadas como áreas de vegetação adensada.

Em que pese alguns aspectos interpretativos do Código Florestal, foi possível delimitar as Áreas de Preservação Permanente determinadas por esse código e caracterizar o tipo de cobertura presente em cada classe de APP. Predominam APP de topo de morro (64\% de todas APP) que se encontram principalmente cobertas por pastagem degradada e solo exposto, contrariando o que preconiza o código florestal. De fato, pastagem é a classe mais frequiente em todas as APP e ocupa em toda a bacia $24 \%$ de sua área.

Os cálculos das variáveis morfométricas, auxiliados pelo ferramental do SIG, permitiram a caracterização física da microbacia do Ribeirão Grande, indicando suscetibilidade à inundação e um alto potencial de erosão hídrica decorrente do escoamento superficial favorecido por áreas de pastagem.

\section{Referências Bibliográficas}

BRASIL. Decreto-lei no 4.771, de 15 de setembro de 1965. Institui o Novo Código Florestal Brasileiro e dá outras providencias. DOU de 16 de setembro de 1965. Brasília DF. 1965.

BRASIL. Conselho Nacional do Meio Ambiente. Resolução no 303, de 20 de março de 2002. Dispõe sobre parâmetros, definições e limites de Áreas de Preservação Permanente. DOU de 13 de maio de 2002. Brasília DF, 2002.

CATELANI, C. de S.; BATISTA, G. T. Mapeamento das Áreas de Preservação Permanente do município de Santo Antonio do Pinhal, SP: um subsídio à preservação ambiental. Revista Ambi-Água, v. 2, n. 1, p. 30-43, 2007. 
CHANDER, G.; MARKHAM, B. L.; HELDER, D. L. Summary of current radiometric calibration coefficients for Landsat MSS, TM, ETM+, and EO-1 ALI sensors. Remote Sensing of Environment, v. 113, p. 893-903, 2009.

CHRISTOFOLETTI, A. Análise morfométrica das bacias hidrográficas. Notícias Geomorfológicas, v.9, n.18, p.19-34, 1969.

CHRISTOFOLETTI, A. Geomorfologia, 2ed. São Paulo: Edgard Blucher Ltda, 1974. 188 p.

Civco, D. L.; Garcia, A. R.; Warner, G.S. Key steps to effective watershed characterization. GIS World, Nov.95, p. 62-67, 1995.

FONTES, A. L. Caracterização geoambiental da bacia do rio Japaratuba - SE, Rio Claro. 1997. 283 p. Tese (Doutorado) - Instituto de Geociências e Ciências Exatas, Universidade Estadual Paulista. Rio claro. 1997.

HORTON, R. E. Erosional development of streams and their drainage basins: hydrophysical approach to quantitative morphology. Bulletin of the geological Society of América, v. 56, p. 275-370, 1945.

IBGE - Instituto Brasileiro de Geografia e Estatística. Mapas topográficos: Folhas SF-23-YB-V-2, SF-23-Y-B-V-4, SF-23-Y-B-VI-1, SF-23-Y-B-VI-3. Rio de Janeiro, IBGE. Escala 1:50.000. mapa color. $60 \times 70 \mathrm{~cm} .1991$.

MIRANDA, E. E. Brasil em Relevo. Campinas: Embrapa Monitoramento por Satélite, 2005. Disponível em: <http://www.relevobr.cnpm.embrapa.br>. Acesso em: 14 set. 2009.

OLIVEIRA, I. S.; BATISTA, G. T.; CATELANI, C. S. Minicurso de Área de Preservação Permanente (APP). In: Material didático utilizado no minicurso sobre APP ministrado no Encontro Água \& Floresta: O Estado da Arte em Educação Ambiental, realizado pela Secretaria Estadual do Meio Ambiente (SMA/SP) e Universidade de Taubaté, 7-9 de novembro de 2006, Taubaté, SP. Disponível em: http://hdl.handle.net/2315/66. Acesso em: 13 Set. 2008 .

PATTON, P. C.; BAKER, V. R. Morphometry and floods in small drainage basins subject to diverse hydrogeomorphic controls. Water Resources Research. v.12, n.5, p.941-952, 1976.

SCHUMM, S. A. Evolution of drainage systems and slopes in badlands at Perth Amboy, New Jersey. Bulletin of the geological Society of América, v. 67, p. 597-646, 1956.

SHENG, T. C.; BARRETT, R. E.; MITCHELL, T. R. Using geographic information systems for watershed classification and rating in developing countries. Journal of Soil and Water Conservation, v. 52, n. 2, p.84-89,1997.

SILVA, D. D.; PRUSKI, F. F. Gestão de recursos hídricos: aspectos legais, econômicos, administrativos e sociais. Viçosa: Universidade Federal de Viçosa, 2005. 659 p.

TAVARES, A. C.; QUEIROZ, A.N. Análise geomorfológica da bacia do Ribeirão Claro. Boletim de Geografia Teorética, v. 11, n. 21-22, p.47-64, 1981.

VILLELA, S. M.; MATTOS, A. Hidrologia aplicada. São Paulo: McGraw-Hill do Brasil, 1980. $250 \mathrm{p}$. 